Fifth International Conference on Sustainable Construction Materials and

Technologies. http://www.claisse.info/Proceedings.htm

\title{
COMPATIBILIZATION OF NATURAL FIBERS AS REINFORCEMENT OF POLYMERIC MATRICES
}

P. Luna ${ }^{(1)(*)}$, J. Lizarazo-Marriaga ${ }^{(2)}$, A. Mariño ${ }^{(3)}$

(1) MSc., PhD Student, Universidad Nacional de Colombia, Engineering Faculty, Bogotá, Colombia.plunat@unal.edu.co

(2) PhD. Prof., Universidad Nacional de Colombia, Engineering Faculty, Bogotá, Colombia. jmlizarazom@unal.edu.co

(3) PhD. Prof., Universidad Nacional de Colombia, Science Faculty, Colombia. amarinoca@unal.edu.co

(*) corresponding author: plunat@unal.edu.co

\begin{abstract}
Natural fibers have become a valuable resource in the composite industry; however, their use is limited due to their low compatibility with traditional polymeric matrices. That low compatibility promotes low mechanical strength in the composite material. In order to avoid this, it is necessary to treat the reinforcement material or the matrix before the composite manufacturing. This paper presents the results of a research aimed to study the effect of two compatibilization techniques applied to natural fibers, on the mechanical properties of the composite. The analyzed techniques were sodium hydroxide $(\mathrm{NaOH})$ baths acting as coupling agent, as well as treatments using a dry etching plasma (physical sputtering). Natural fibers employed in this research were obtained from Guadua angustifolia bamboo culms, and the manufacturing of the composite was accomplished using a manual moulding technique and a polyester matrix. Results revealed that treatments using sodium hydroxide decrease the fibers' tensile strength, while the dry etching plasma treatments do not appear to affect their tensile strength. Moreover, both compatibilization techniques improve guaduapolyester composites' strength. It is believed that this increment is the result of the increase in the bonding strength between composite's phases.
\end{abstract}

Keywords: Natural fibers, compatibilization techniques, composite materials, sodium hydroxide, dry etching plasma, bamboo Guadua angustifolia

\section{INTRODUCTION}

Since 1990s, composite materials reinforced by using natural fibers (CNF) have been used in various industrial applications, as an alternative to those reinforced with synthetic-origin fibers (CSF) [1]. The main advantage from using natural fibers as reinforcement of different matrices is their biodegradability, apart from other technical aspects such as low density, abundant availability, corrosion resistivity, low cost and non/abrasive processing characteristics, which make natural fibers an important alternative for many engineering applications [2]. In addition, according to Joshi et al. [3], CNFs are environmentally superior to CSFs due to three basic aspects: (1) the production of natural fiber produces lower environmental impacts compared to the production of synthetic fibers; (2) CNFs have higher 
fiber content for equivalent performance, which reduces the amount of matrix needed, which in most cases are highly polluting; and (3) the end-of-life incineration of natural fibers generates energy and carbon credits.

Composite materials are formed by a dispersed phase, called reinforcement material or fibers, embedded into a continuous phase, called matrix. The mechanical properties of composite materials depend on the properties of fibers and matrices. Additionally, the adequate mechanical performance of composites is influenced by all physico-chemical interactions among composite constituents in the interfacial region, where fibers and matrices are in direct contact [4], [5].

The main disadvantage from using natural fibers as reinforcement of polymeric matrices is the low chemical compatibility between composite phases, due to the hydrophilic behavior of fibers and the hydrophobic behavior of polymers [6]-[8]. The low chemical compatibility brings about an inadequate mechanical behavior of the composite material due to the low adherence between phases [9]. In literature, there are two main procedures in order to overcome the limitations arising from using natural fibers as reinforcement of polymers. The first procedure is focused on the modification of the physico-chemical properties of polymer matrices, and the second one on the modification of the physico-chemical properties of fibers [10]. The second procedure is more commonly used for industrial applications. The modification of the physico-chemical properties of fibers can be achieved by using coupling agents [11]-[13], making a graft polymerization of monomers compatible with the polymer matrix [14], or using plasma treatments [15]-[17]

Treating natural fibers by using coupling agents has the main purpose of removing hydroxyl groups present at the hemicellulose, lignin and amorphous cellulose of natural fibers, which supply its hydrophilic behavior. Also, this treatment expose the crystalline cellulose that could react with the polymer matrix employed [18]-[20]. The main disadvantage from using this kind of treatments is that they could also react with the hydroxyl groups at the crystalline cellulose region, thus producing a reconfiguration of the fiber's structure that diminish its mechanical properties [1], [18], [21]. By using this technique, the compatibilization among composite constituents can be achieved following a purely chemical approach.

Another innovative alternative to modifying the physico-chemical properties of fibers is by using plasma treatments. Plasma consists of the ionization of a gas or mixture of gasses, by applying an electric field to the gas [16], [22]. As a general point of view, there are three main purposes for applying plasma treatments in material science: surface functionalization, thin film deposition, and etching [22]-[24]. Etching processes are focused on removing some material from the surface of the treated substrate [25]. The removal can be achieved by using a physical sputtering procedure, in which the material is removed by purely physical processes, due to the ion bombardment from the species present in plasma [17]. The main advantage from using plasma treatments is that the alterations do not affect the bulk properties of the material [26]-[29]. By using this technique, the compatibilization among composite constituents is achieved following a purely physical approach, by increasing the mechanical grip between the fibers and the polymer.

This paper presents the results of a research aimed to use two different techniques for the 
compatibilization between polymers and natural fibers, focused on the modification of the physico-chemical properties of fibers. The researched techniques were sodium hydroxide $(\mathrm{NaOH})$ baths acting as coupling agent, as well as treatments using a dry etching plasma (physical sputtering). The natural fibers were obtained from Guadua angustifolia (guadua) bamboo culms. The establishment of the influence from used compatibilization techniques on the mechanical behavior of guadua fibers and a polymer composite material, were made through mechanical tests. The composite material was fabricated using the manual moulding technique and a polyester matrix.

\section{EXPERIMENTAL PROGRAM}

\section{Guadua Fiber Obtainment}

Guadua fibers were obtained by using a chemical-mechanical procedure schematically shown on Figure 1. The main purpose of the chemical procedure was to soft the culms, after which a mechanical procedure was followed to separate the fibers. The fiber extraction procedure starts dividing the culm in longitudinal rectangular strips, which were polished in order to remove the protuberance at node and to eliminate the culm cortex. Then, the chemical softening of polished strips was carried out by immersing them during $3 \mathrm{~h}$ in a $2.5 \%$ concentration $\mathrm{NaOH}$ solution, previously heated at $80^{\circ} \mathrm{C}$, in which they were maintained during all the immersion time. In order to obtain the fibers, a mechanical process using the machine described on [30] was employed. All obtained fibers were carefully washed using tap water, then they were dried at laboratory temperature. In this research, the bottom part of guadua culms was used to obtain the fibers. The average length and diameter of obtained fibers were $91.6 \mathrm{~mm}$ and $0.22 \mu \mathrm{m}$, respectively.

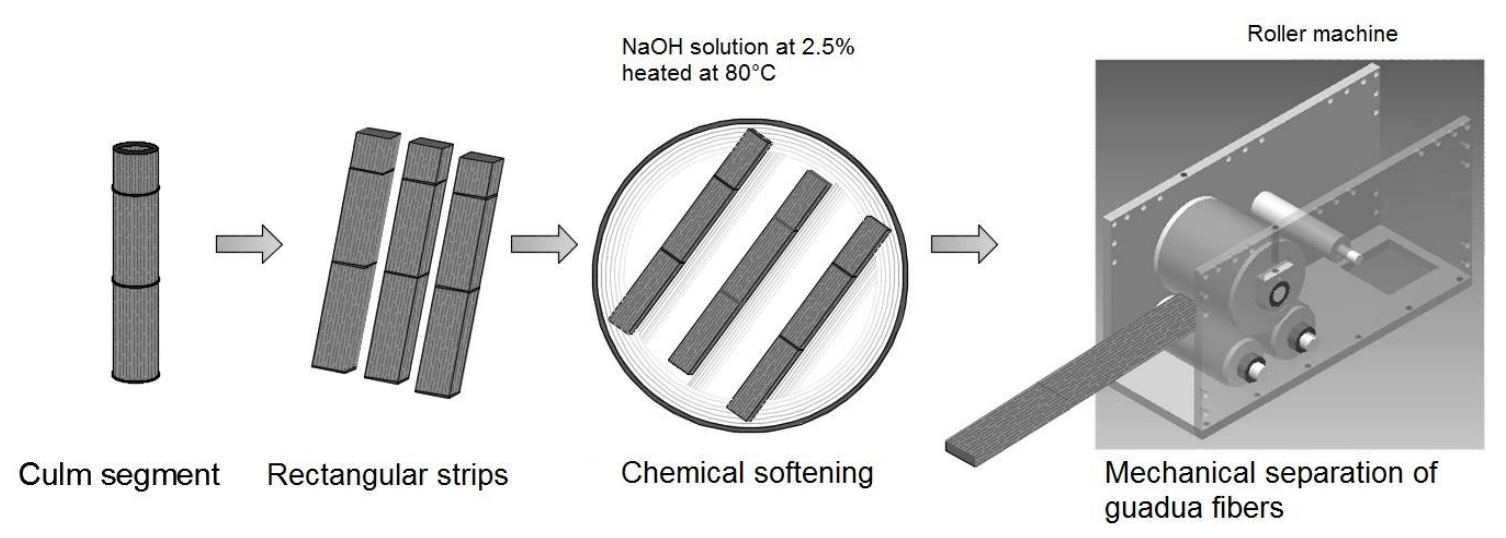

Figure 1. Guadua fibers extraction procedure

\section{Modification of Physico-Chemical Properties of Guadua Fibers}

The physyco-chemical properties of guadua fibers were modified in order to increase their compatibility with polyester matrix. In this research two different treatments were performed in order to accomplish this modification: sodium hydroxide $(\mathrm{NaOH})$ baths acting as coupling agent, and dry etching plasma (physical sputtering) treatments. Guadua fibers were treated using both techniques separately. 
In $\mathrm{NaOH}$ treatments, guadua fibers were immersed in solution concentrations of $1 \%, 2.5 \%$, $5 \%$ and $10 \%$ during $1 \mathrm{~h}$. After this time, treated fibers were carefully and deeply washed using tap water.

In dry etching plasma treatments, guadua fibers were treated at different times of exposure to ion bombardment using the same energy. These treatments were performed using a DC sputtering (etching) system and employing Argon (Ar) gas to plasma generation. In a previous research [31], it was concluded that treating guadua fibers below $1000 \mathrm{~s}$ does not increase the mechanical strength of guadua-polyester composites. Thus, in this research the guadua fibers times of exposure to ion bombardment were 400, 10001500 and $2000 \mathrm{~s}$. All treatments were carried out using an average current of $30 \pm 3 \mathrm{~mA}$ and a working pressure of $10^{-2} \mathrm{kPa}$.

\section{Composite Fabrication}

Compression molding was the manufacturing technique used in this research. Composite components, i.e. guadua fibers and polyester resin in liquid state, were inserted into a closed mold which was able to apply a compression load, in order to spread the liquid resin throughout the mold and evacuate the trapped air. The compression load was maintained constant until the resin was completely cured. Initially, guadua fibers were randomly placed into the mold. Then, the polyester resin, previously mixed with the catalyst (added at 2\%) was poured. The resin used in this research was an unsaturated polyester featuring a 555commercial reference, while methyl ethyl ketone peroxide (MEKP) was used as catalyst. Figure 2 shows guadua-polyester composite square plates featuring $200 \mathrm{~mm}$ of length and $10 \mathrm{~mm}$ of thickness, which were obtained using this methodology, . All composite plates were fabricated using a $6 \%$ weight fiber proportion .

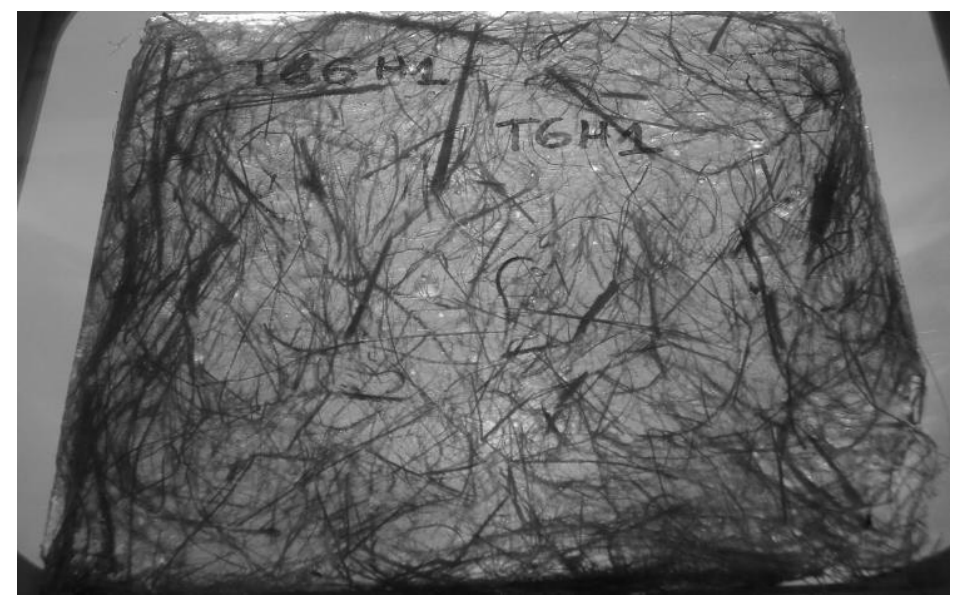

Figure 2. Guadua-polyester composite square plate

\section{Fibers Tensile Tests}

The influence from applied compatibilization treatments on the guadua fiber tensile strength, was established through tensile testing on non-treated and treated fibers. In order to obtain results statistically representing fibers' mechanical strength, 16 replicates were tested for each treatment condition; this sample size was calculated based on an expected fiber tensile strength $20 \mathrm{MPa}$ error, with a confidence level of $90 \%$. All tests were performed following 
the ASTM C1557-14 procedure, using a load rate of $1.5 \mathrm{~mm} / \mathrm{min}$. Before mechanical tests, all samples were placed on paper frames as shown in Figure 3, in order to avoid axial load deviation; and after positioning said frames on testing grips, they were carefully cut.

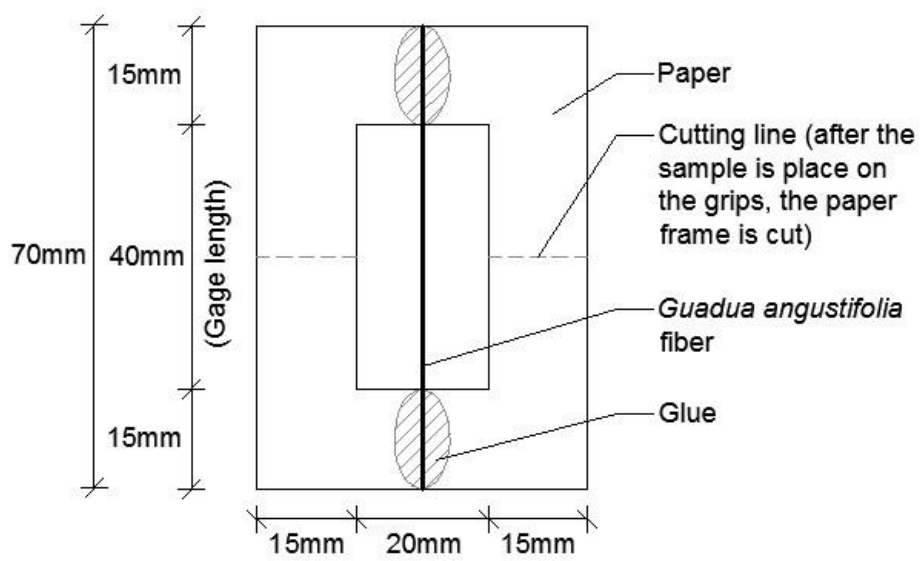

Figure 3. Paper frame used on fibers tensile tests

Equation 1 was used to calculate the tensile strength $\left(\sigma^{f}\right)$ of each tested fiber. In this equation, $P_{\text {max }}^{f}$ and $A^{f}$ correspond to failure load and cross-sectional area of each fiber, respectively. The cross-sectional area of each fiber was determined at its fracture plane, using the methodology established on a previous research [32], which allows to determine more accurate measurements.

$\sigma^{f}=\frac{P_{\max }^{f}}{A^{f}}$

\section{Composite Tensile Tests}

In order to establish the influence from applied fiber treatments on the guadua-polyester composites' strength, tensile tests on composite samples fabricated using non-treated and treated fibers were performed. For each treatment condition, 8 samples were tested; this sample size was calculated based on an expected composite tensile strength $2 \mathrm{MPa}$ error, with a confidence level of 90\%. Tests were made following the ASTM D3039/D3039M-08 procedure. All samples were prepared by cutting the square plates fabricated following the methodology described above. Figure 4 shows the average dimensions of composite samples and the test setup.

The composite tensile strength $\left(\sigma^{c}\right)$ was calculated using Equation 2, where $P_{\max }^{c}$ and $A^{c}$ are the composite's failure load and failure area in each sample tested. The failure area was determined by measuring the width and thickness of the failure plane of each sample, and was computed by assuming a rectangular shape.

$\sigma^{c}=\frac{P_{\max }^{c}}{A^{c}}$ 

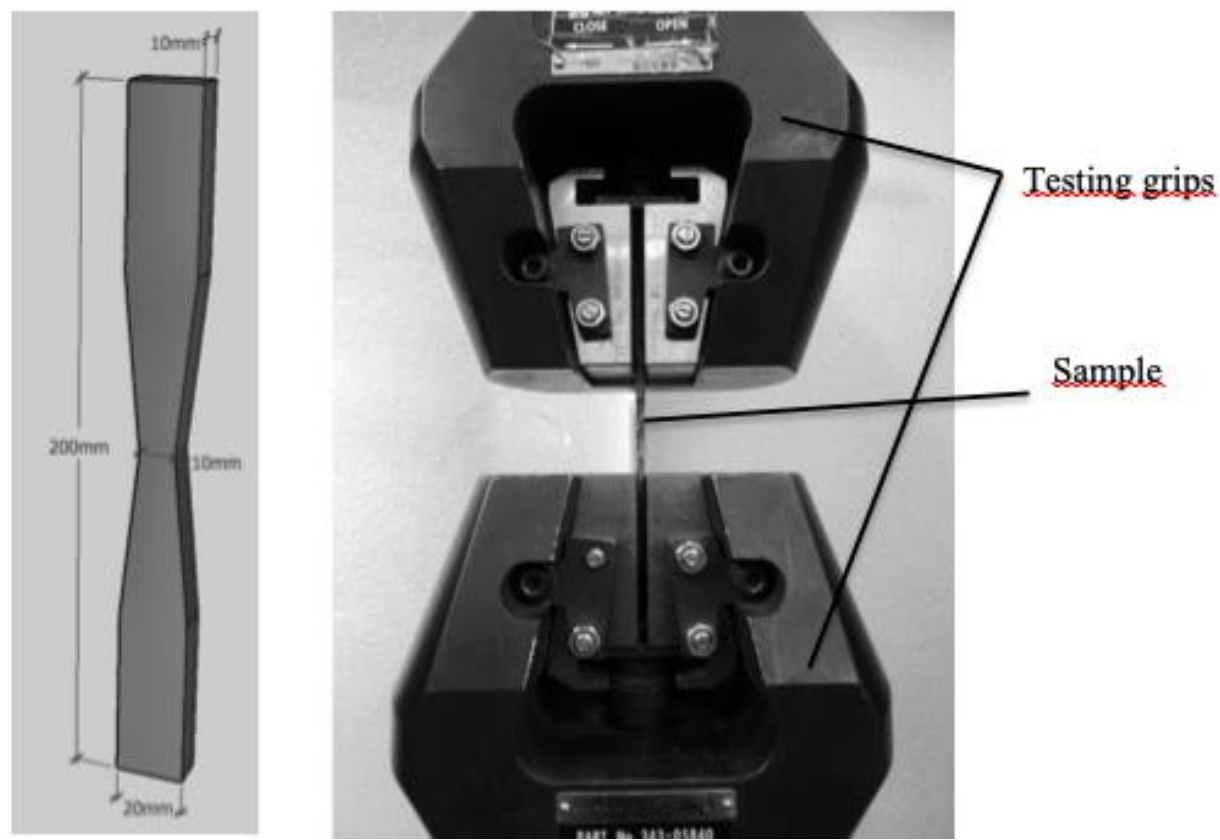

Figure 4. Average dimension and test set-up for guadua-polyester composite tensile tests

\section{RESULTS AND DISCUSSION}

Figure 5 shows the results of average tensile strength of guadua fibers treated with $\mathrm{NaOH}$ and dry etching plasma. Showed values did not include the outliers, which were identified using boxplots. In this figure, bars identified by $\mathrm{H} 1, \mathrm{H} 2.5, \mathrm{H} 5$ and $\mathrm{H} 10$ correspond to results obtained for fibers treated using $\mathrm{NaOH}$ at the different solution concentrations. On the other hand, bars identified by P400, P1000, P1500 and P2000 correspond to results obtained for fibers treated using dry etching plasma at the different exposure times. Also, Figure 5 shows each sample group's standard deviation as error bars.

When separately analyzing each column of Figure 5, guadua fibers show high tensile strength variability, which is quite characteristic of natural fibers. According to [33], this variation is the result of three main factors: test parameters/conditions, plant characteristics, and area measurements. Due that in this research similar parameters and conditions during all tests are used, as well as a methodology to measure the cross-sectional area with high accuracy, the variation could be mainly attributed to differences in raw material (guadua culms), fiber's microstructure, and to the errors inherent in the experimental procedure. The non-treated fibers' standard deviation is lower as compared to that from applied treatments. This difference may arise from anisotropic changes induced by applied treatments on fiber's microstructure.

As shown in Figure 5, both compatibilization treatments applied on guadua fibers decrease the tensile strength of treated fibers; the decrease is more significant for $\mathrm{NaOH}$ treatment as compared to the decrease from dry etching plasma. 


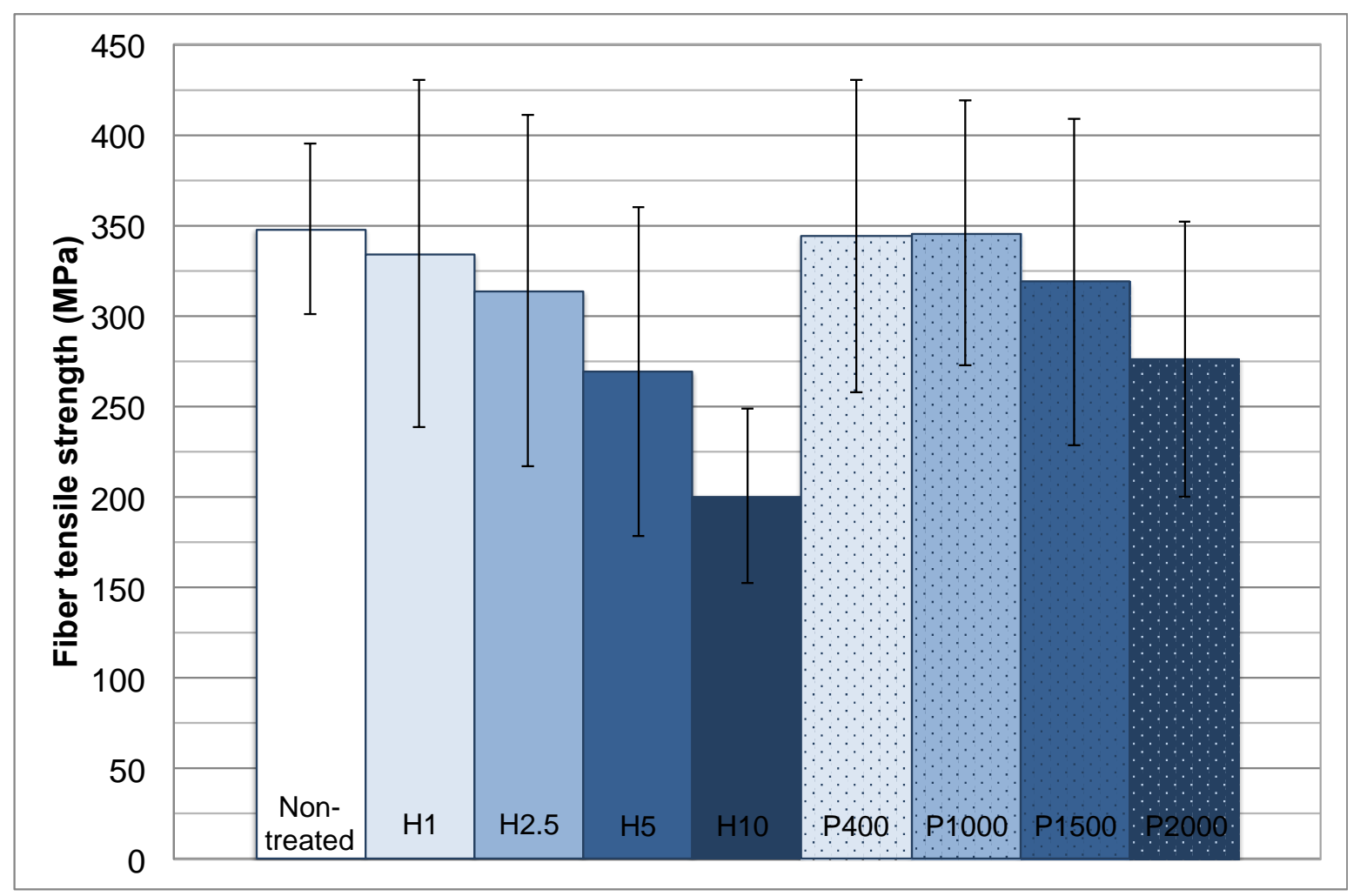

Figure 5. Average tensile strength for treated guadua fibers

Figure 6 shows the average tensile strength results of guadua-polyester composite. Showed values do not include the outliers, which were identified using boxplots. As in Figure 5, the bars identified by $\mathrm{H} 1, \mathrm{H} 2.5, \mathrm{H} 5$ and $\mathrm{H} 10$ in this figure correspond to the results obtained for composites fabricated using fibers treated with $\mathrm{NaOH}$ at the different solution concentrations, and the bars identified by P400, P1000, P1500 and P2000 correspond to the results obtained for composites fabricated using fibers treated with dry etching plasma at the different exposure times. Also, the error bars in this figure show each data set's standard deviation.

When comparing the values showed in Figures 5 and 6, it can be noticed that the guaduapolyester composite's tensile strength is clearly lower than the guadua fibers' tensile strength. This behavior was expected, since as shown in Figure 2, the composite material reinforcement was randomly applied, thus reducing the fibers' effectiveness to resist loads. Also, it can be seen that the composites' standard deviation is lower than the one obtained for fibers. Since the reinforcement percentage is low, the variation is controlled by polyester resin, which is produced in an industrialized process that could guarantee more standardized properties.

It can be seen that all applied compatibilization treatments increased guadua-polyester composites' tensile strength. In general terms, the composite tensile strength increase for both compatibilization treatments is similar. Regarding $\mathrm{NaOH}$ treatments, the maximum tensile strength was obtained for composites reinforced with fibers holding $2.5 \%$ solution concentration. In the case of dry etching plasma treatments, the maximum tensile strength was obtained for composites reinforced with fibers treated during $1000 \mathrm{~s}$. 


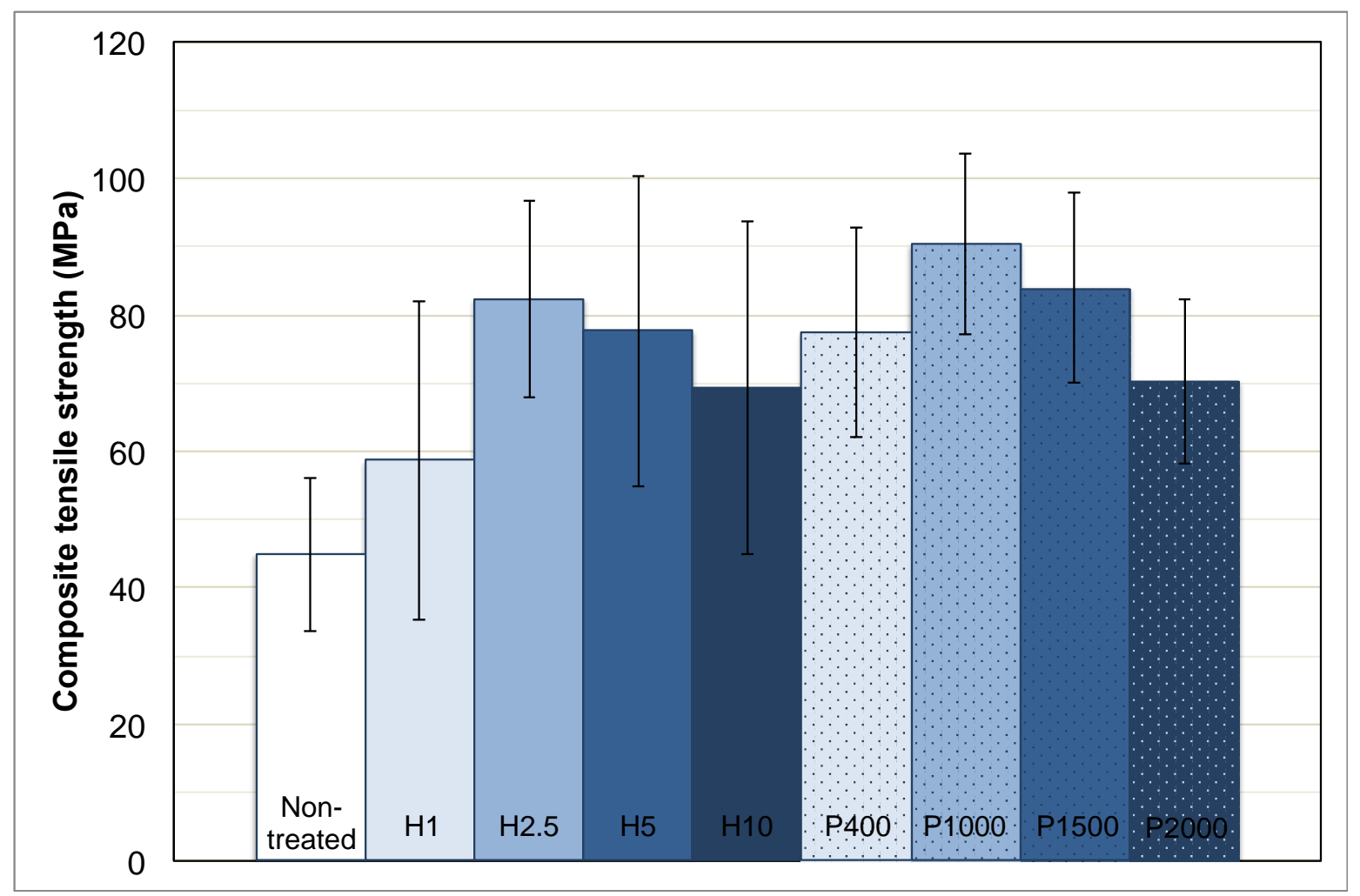

Figure 6. Average tensile strength for guadua-polyester composite

A statistical analysis was performed in order to identify significant differences between average results obtained for fibers and guadua-polyester composites when applying the used compatibilization techniques. Initially, through the Shapiro-Wilk tests, it could be verified whether each data set distribution was normal. The homoscedasticity was verified among the data collected through the Levene's test. An ANOVA analysis was applied in the cases in order to fulfill both normality criteria and homoscedasticity; as for the opposing cases, the Kruskal-Wallis test was used. In all cases, the significance level used was 0.05.

The Kruskal-Wallis test performed for average fibers' tensile strength pointed out variations among some of the values obtained. However, there are no differences among the average fiber's strength regarding non-treated, H1, H2.5 and all cases using dry etching plasma. In contrast, the tensile strengths obtained for H5 and H10 cases are substantially lower as compared to other cases. A previous research revealed similar results for the same compatibilization technique [34], [35]. Treating natural fibers with $\mathrm{NaOH}$ could cause a degradation of their crystalline cellulose, which is the constituent that governs the mechanical performance thereof [36], [37]. According to obtained results, this degradation starts to be significant at values equal to 5\% solution concentration and higher. As previously mentioned, the main advantage of plasma treatments is that they do not affect the bulk properties of treated material.

Similarly, in the case of guadua-polyester composites, ANOVA analysis revealed significant differences among some obtained values. The lower tensile strength was obtained for 
composites samples fabricated using non-treated and H1 fibers, while the higher values were obtained for samples using P1000. Statistically, the average strengths for the samples using $\mathrm{H} 2.5$, H5, P400 and P1500 fibers are similar, which also happens to be the case for the samples using $\mathrm{H} 10$ and $\mathrm{P} 2000$ fibers.

\section{CONCLUSIONS}

The studied techniques used in this research to modify the physico-chemical properties of fibers, can be used to make a polyester matrix more compatible with guadua fibers. Tensile strength obtained for composites fabricated using non-treated guadua fibers is lower than the strength obtained for samples fabricated using treated fibers. The maximum composite tensile strength was obtained for samples fabricated using fibers treated with dry etching plasma during 1000s.

From the statistical analysis, it can be concluded that treating guadua fibers with $\mathrm{NaOH}$ could decreased the fibers' tensile strength. This decrease could be the result of a degradation of the crystalline cellulose caused by the chemical treatment. On the other hand, treating guadua fibers with dry etching plasma does not affect their tensile strength. As explained in the related literature, plasma alterations do not affect the bulk properties of treated materials.

\section{ACKNOWLEDMENTS}

The authors acknowledge the support provided by Colciencias (funding 6172), and Universidad Nacional de Colombia (funding DIB 34835).

\section{REFERENCES}

[1] O. Faruk, A. Bledzki, H. Fink, and M. Sain, "Biocomposites reinforced with natural fibers: 2000-2010," Prog. Polym. Sci., vol. 37, no. 11, pp. 1552-1596, Nov. 2012.

[2] G. S. Divya and B. Suresha, "Recent developments of Natural Fiber Reinforced Thermoset Polymer Composites and their Mechanical Properties," Indian J. Adv. Chem. Sci., pp. 267-274, 2016.

[3] S. V. Joshi, L. T. Drzal, A. K. Mohanty, and S. Arora, "Are natural fiber composites environmentally superior to glass fiber reinforced composites?," Compos. Part A Appl. Sci. Manuf., vol. 35, no. 3, pp. 371-376, Mar. 2004.

[4] I. Daniel and O. Ishai, Engineering mechanics of composite materials, Primera Ed. Oxford University Press, 1994.

[5] L. C. Bank, Composites for Construction. 2006.

[6] A. Bledzki, S. Reihmane, and J. Gassan, "Properties and modification methods for vegetable fibers for natural fiber composites," J. Appl. Polym. Sci., vol. 59, no. 8, pp. 1329-1336, Feb. 1996.

[7] J. George, M. Sreekala, and S. Thomas, "A review on interface modification and characterization of natural fiber reinforced plastic composites," Polym. Eng. Sci., vol. 41, no. 9, pp. 1471-1485, Sep. 2001.

[8] Y. Yu, X. Huang, and W. Yu, "A novel process to improve yield and mechanical 
performance of bamboo fiber reinforced composite via mechanical treatments," Compos. Part B Eng., Aug. 2013.

[9] V. Tserki, N. E. Zafeiropoulos, F. Simon, and C. Panayiotou, "A study of the effect of acetylation and propionylation surface treatments on natural fibres," Compos. Part A Appl. Sci. Manuf., vol. 36, no. 8, pp. 1110-1118, Aug. 2005.

[10] A. Valadez-Gonzalez, J. M. Cervantes-Uc, R. Olayo, and P. J. Herrera-Franco, "Effect of fiber surface treatment on the fiber-matrix bond strength of natural fiber reinforced composites," Compos. Part B Eng., vol. 30, no. 3, pp. 309-320, 1999.

[11] S. Lee, I. Kang, B. Park, G. Doh, and B. Park, "Effects of filler and coupling agent on the properties of bamboo fiber-reinforced polypropylene composites," J. Reinf. Plast. Compos., vol. 28, no. 21, pp. 2589-2604, 2009.

[12] P. K. Kushwaha and R. Kumar, "Influence of chemical treatments on the mechanical and water absorption properties of bamboo fiber composites," J. Reinf. Plast. Compos., vol. 30, no. 1, pp. 73-85, Sep. 2010.

[13] H. Kim, K. Okubo, T. Fujii, and K. Takemura, "Influence of fiber extraction and surface modification on mechanical properties of green composites with bamboo fiber," J. Adhes. Sci. Technol., vol. 27, no. 12, pp. 1348-1358, 2013.

[14] A. Valadez, "Efecto del tratamiento superficial de fibras de Henequén sobre la resistencia interfacial fibra-matriz y en las propiedades efectivas de materiales compuestos termoplásticos," Universidad Autónoma Metropolitana, México D.F, 1999.

[15] J. Gassan and V. Gutowski, "Effects of corona discharge and UV treatment on the properties of jute-fibre epoxy composites," Compos. Sci. Technol., vol. 60, pp. 2857-2863, 2000.

[16] M. Morshed, M. Alam, and S. Daniels, "Plasma Treatment of Natural Jute Fibre by RIE 80 plus Plasma Tool," Plasma Sci. Technol., vol. 325, 2010.

[17] P. Luna, A. Mariño, J. Lizarazo-Marriaga, and O. Beltrán, "Dry etching plasma applied to fique fibers : influence on their mechanical properties and surface appearance," Procedia Eng., vol. 200, pp. 141-147, 2017.

[18] M. Kabir, H. Wang, K. Lau, and F. Cardona, "Tensile Properties of Chemically Treated Hemp Fibres as Reinforcement for Composites," Compos. Part B Eng., vol. 53, pp. 362-368, 2013.

[19] X. Li, L. Tabil, and S. Panigrahi, "Chemical Treatments of Natural Fiber for Use in Natural Fiber-Reinforced Composites: A Review," J. Polym. Environ., vol. 15, no. 1, pp. 25-33, Jan. 2007.

[20] M. Guimarães Junior, K. Monteiro Novack, and V. Botaro, "Bamboo pulp treated with $\mathrm{NaOH}$ and benzophenone tetracarboxylic dianhydride as reinforcement of new polymerics materials," Rev. Latinoam. Metal. y Mater., vol. 34, pp. 196-208, 2013.

[21] A. Bledzki and J. Gassan, "Composites reinforced with cellulose based fibres," Prog. Polym. Sci., vol. 24, pp. 221-274, 1999.

[22] J. M. Albella, Ed., Láminas delgadas y recubrimientos: preparación, propiedades y aplicaciones. Madrid, España: Consejo Superior de Investigaciones Científicas, 2003.

[23] R. Li, L. Ye, and Y. Y. Mai, "Application of plasma technologies in fibre-reinforced polymer composites: a review of recent developments," Compos. Part A Appl. Sci. Manuf., vol. 28, no. 1997, pp. 73-86, 1997.

[24] F. S. Denes and S. Manolache, "Macromolecular plasma-chemistry: An emerging 
field of polymer science," Prog. Polym. Sci., vol. 29, no. 8, pp. 815-885, 2004.

[25] A. Bogaerts, E. Neyts, R. Gijbels, and J. Van der Mullen, "Gas discharge plasmas and their applications," Spectrochim. Acta - Part B At. Spectrosc., vol. 57, no. 4, pp. 609-658, 2002.

[26] C. M. G. Carlsson and G. Stroem, "Reduction and Oxidation of Cellulose Surfaces by Means of Cold-Plasma," Langmuir, vol. 7, no. 11, pp. 2492-2497, 1991.

[27] T. H. C. H. C. Costa, M. C. C. Feitor, C. Alves Junior, and C. M. M. Bezerra, "Caracterização de filmes de poliéster modificados por plasma de $\mathrm{O} 2$ a baixa pressão," Rev. Matéria, vol. 13, no. 1, pp. 65-76, 2008.

[28] M. de Oliveira, H. Reis, J. C. Pereira, C. L. de Brito, M. Rodrigues, and C. Alves, "O Uso Do Plasma De Nitrogênio Para Modificação Superficial Em Membranas De Quitosana," Rev. Bras. Inovação Tecnológica em Saúde, pp. 1-15, 2011.

[29] B. N. Barra, S. F. Santos, P. V. a. Bergo, C. Alves, K. Ghavami, and H. Savastano, "Residual sisal fibers treated by methane cold plasma discharge for potential application in cement based material," Ind. Crops Prod., vol. 77, pp. 691-702, 2015.

[30] P. Luna and J. Lizarazo-Marriaga, "An extraction methodology of Guadua angustifolia bamboo fibers," in 6th Amazon \& Pacific Green Materials Congress and Sustainable Construction Materials LAT-RILEM Conference, 2016.

[31] P. Luna, J. Lizarazo-Marriaga, A. Mariño, and M. Rivas, “Assessment of two compatibilization techniques for Guadua angustifolia bamboo fibers as reinforcement of polymeric matrices," in II Congreso Latinoamericano de Estructuras de Madera y II Congreso Ibero-Latinoamericano de la madera en la Construcción (CLEM+CIMAD 2017), 2017, pp. 1-6.

[32] P. Luna and J. Lizarazo-Marriaga, "Proposed Method for Determining CrossSectional Area of Guadua angustifolia Bamboo Fibers," J. Nat. Fibers, vol. 00, no. 00, pp. 1-10, 2017.

[33] F. de Andrade, N. Chawla, and R. D. Toledo Filho, "Tensile behavior of high performance natural (sisal) fibers," Compos. Sci. Technol., vol. 68, no. 15-16, pp. 3438-3443, 2008.

[34] P. Luna, J. Lizarazo-Marriaga, and A. Mariño, "Guadua angustifolia bamboo fibers as reinforcement of polymeric matrices: An exploratory study," Constr. Build. Mater., vol. 116, pp. 93-97, 2016.

[35] P. Luna, J. Lizarazo-Marriaga, and A. Mariño, "Preliminary study on the compatibilization techniques of natural fibers as reinforcement of polymeric matrices," in Sustainable Construction Materials and Technologies (SCMT4), 2016.

[36] M. Hughes, "Defects in natural fibres: their origin, characteristics and implications for natural fibre-reinforced composites," J. Mater. Sci., vol. 47, no. 2, pp. 599-609, Oct. 2012.

[37] R. Fangueiro and S. Rana, Natural Fibres: advances in science and technology towards industrial applications, vol. 12. Springer, 2016. 